\title{
Adjuvant treatment recommendations for patients with ER-positive/HER2-negative early breast cancer by Swiss tumor boards using the 21-gene recurrence score (SAKK 26/10)
}

Bernhard C. Pestalozzi ${ }^{1 *}$, Christoph Tausch², Konstantin J. Dedes ${ }^{1}$, Christoph Rochlitz ${ }^{3}$, Stefan Zimmermann ${ }^{4}$, Roger von Moos ${ }^{5}$, Ralph Winterhalder ${ }^{6}$, Thomas Ruhstaller ${ }^{7}$, Andreas Mueller ${ }^{8}$, Katharina Buser ${ }^{9}$, Markus Borner ${ }^{10}$, Urban Novak ${ }^{11}$, Catrina Uhlmann Nussbaum ${ }^{12}$, Bettina Seifert ${ }^{13}$, Martin Bigler ${ }^{14}$, Vincent Bize ${ }^{14}$,

Simona Berardi Vilei ${ }^{14}$, Christoph Rageth ${ }^{2}$, Stefan Aebi ${ }^{6}$ and The Swiss Group for Clinical Cancer Research (SAKK)

\begin{abstract}
Background: To evaluate the effect of Recurrence Score ${ }^{\circledR}$ results (RS; Oncotype DX ${ }^{\circledast}$ multigene assay ODX) on treatment recommendations by Swiss multidisciplinary tumor boards (TB).

Methods: SAKK 26/10 is a multicenter, prospective cohort study of early breast cancer patients: Eligibility: RO-resection, $\geq 10 \%$ ER+ malignant cells, HER2-, pN0/pN1a. Patients were stratified into low-risk (LR) and non-low-risk (NLR) groups based on involved nodes (0 vs 1-3) and five additional predefined risk factors. Recommendations were classified as hormonal therapy $(H T)$ or chemotherapy plus $H T(C T+H T)$. Investigators were blinded to the statistical analysis plan. A $5 \% / 10 \%$ rate of recommendation change in LR/NLR groups, respectively, was assumed independently of RS (null hypotheses).
\end{abstract}

Results: Two hundred twenty two evaluable patients from 18 centers had TB recommendations before and after consideration of the RS result. A recommendation change occurred in 45 patients $(23 / 154$ (15\%, 95\% Cl 10-22\%) in the LR group and 22/68 (32\%, 95\% Cl 22-45\%) in the NLR group). In both groups the null hypothesis could be rejected (both $p<0.001)$. Specifically, in the LR group, only $5 / 113(4 \%, 95 \% \mathrm{Cl} 1-10 \%)$ with HT had a recommendation change to $\mathrm{CT}+\mathrm{HT}$ after consideration of the RS, while $18 / 41(44 \%, 95 \% \mathrm{Cl} 28-60 \%)$ of patients initially recommended CT + HT were subsequently recommended only HT. In the NLR group, 3/19 (16\%, 95\% Cl 3-40\%) patients were changed from HT to $\mathrm{CT}+\mathrm{HT}$, while 19/48 (40\%, 95\% Cl 26-55\%) were changed from CT + HT to HT.

Conclusion: There was a significant impact of using the RS in the LR and the NLR group but only $4 \%$ of LR patients initially considered for HT had a recommendation change $(R C)$; therefore these patients could forgo ODX testing. A RC was more likely for NLR patients considered for HT. Patients considered for HT + CT have the highest likelihood of a RC based on RS.

Keywords: ER-positive early breast cancer, Adjuvant treatment recommendation, Multigene expression profiling, Recurrence score, Oncotype DX

* Correspondence: bernhard.pestalozzi@usz.ch

'Universitaetsspital Zuerich, Raemistrasse 100, 8091 Zurich, Switzerland

Full list of author information is available at the end of the article 


\section{Background}

While initial trials in unselected women with early-stage ER-positive breast cancer failed to demonstrate a beneficial effect from adding chemotherapy to adjuvant endocrine therapy [1-4], it later became apparent that adjuvant chemo-endocrine therapy does reduce the recurrence rate compared with adjuvant endocrine therapy alone in certain selected populations. One approach to identifying which patients should receive adjuvant CT in addition to adjuvant endocrine therapy was described in the St. Gallen Consensus Highlights in 2009 [5]. The following factors can be used to separate patients with lower and higher risk of relapse and death: Nodal status, primary tumor size, ER/PgR level, histologic tumor grade, proliferation fraction (Ki67), lymphovascular invasion. In addition, the NSABP B-20 [6] and SWOG 8814 [7] trials demonstrated that gene expression profiling is a useful tool for selecting patients who are most likely to benefit from adding chemotherapy to adjuvant treatment in patients with node-negative and node-positive breast cancers, respectively. In both these trials, patients were stratified into three distinct groups following measurement of RNA expression using the ODX assay developed by Genomic Health Incorporated (GHI). The ODX assay is a multigene reverse-transcriptase polymerase chain reaction (RT-PCR) test that analyzes the expression of 21 genes and estimates the 10-year distant breast cancer recurrence risk. The assay was validated in the NSABP B-14 trial, a large, multicenter trial for women with node-negative, ER-positive breast cancer treated with tamoxifen [8]. The ODX assay result Recurrence Score (RS) provides as a continuous variable ranging from 0 to 100 . For statistical analysis, patients are typically grouped into three risk categories based on the RS: low (RS 0-17), intermediate (RS 18-30), and high ( $\mathrm{RS} \geq 31$ ). These categories have been shown to correlate with the rate of distant recurrence in multiple studies in node negative [8-11] and node positive disease $[7,12]$ at 10 years as well as overall survival [8].

The NSABP B-20 trial showed that the benefit of adding chemotherapy (cyclophosphamide, methotrexate, fluorouracil) to tamoxifen was mainly seen in a relatively small group of patients with a high RS $(\geq 31)[6]$. These patients had an absolute decrease in 10-year distant recurrence rate of $28 \%$ with adjuvant chemotherapy plus endocrine therapy compared with adjuvant endocrine therapy alone. Patients in the low and intermediate RS risk groups had no significant benefit from the addition of chemotherapy [6]. Similarly, in the SWOG 8814 (INT0100) trial performed in patients with node-positive breast cancer the benefit of adding cyclophosphamide, doxorubicin, and fluorouracil followed by tamoxifen compared with tamoxifen alone was seen only in patients with high RS [7].

The ODX assay has been available in the US since 2004 as a tool to aid a physician's treatment recommendation for patients with early breast cancer and was recommended by an ASCO expert panel for use in patients with ER-positive early breast cancer in 2007 [13]. TAILORx, a prospective clinical trial, confirmed that patients with node negative breast cancer and a low RS $(<11)$ had a very low risk of distant relapse [11].

Several studies have attempted to analyze the contribution of ODX assay to decisions on adjuvant treatment in patients with ER-positive breast cancer. In an American study of 89 patients with node-negative disease, the assay led to changes in treatment decisions in $31 \%$ of cases [14], although whether design of this study allowed these decision changes to be attributed to the use of the ODX assay was later questioned [15]. Since then, similar studies in Australia [16], Canada [17], Germany [18], France [19], Israel [20], Japan [21], Spain [22], and the United Kingdom [23] have consistently shown that knowledge of the ODX RS changed treatment plans in about $30 \%$ of cases. The majority of changed decisions were due to "de-escalation" from chemotherapy plus endocrine therapy to endocrine therapy alone.

In Switzerland, the ODX assay was not reimbursed until 2015 and was rarely performed. In contrast, Swiss oncologists often used the Ki-67 proliferation assay, expression levels of estrogen and/or progesterone receptor, histological grading and nodal status to support a recommendation for or against adjuvant chemotherapy [24, 25].We studied whether the introduction of the ODX assay impacted on treatment recommendations issued by Swiss multidisciplinary tumor boards.

\section{Methods}

\section{Patient population}

SAKK 26/10 (NCT01926964) is a multicenter, prospective cohort study. Participants had completely resected breast cancer with pathologically confirmed negative margins. Participants also had to have $\geq 10 \%$ ER-positive invasive malignant cells, HER2-negative carcinoma by immunohistochemistry ( 0 or $1+)$ or by FISH (ratio of HER2/Cen $17 \leq 2.0$ ) by local pathology, and a regional lymph node status of pN0 or pN1a (1-3 positive nodes) as determined by axillary dissection or sentinel procedure [26, 27].

Each case was presented at the center's multidisciplinary tumor board where a first recommendation on adjuvant systemic treatment was issued. The following items were required for baseline data collection ("pre-registration" step): pathologic maximum tumor diameter (in $\mathrm{mm}$ ), percentage of ER-positive and progesterone (PgR)-positive invasive tumor cells, Ki-67 proliferation rate (MIB-1 antibody), and the modified Bloom-Richardson-Elston (BRE) grade. In addition, for study eligibility ("registration" step), the patient had to be considered suitable to receive adjuvant chemotherapy, have a WHO performance status 
$0-1$, and have sufficient invasive breast cancer tissue available to prepare 39 tissue sections (thickness $5 \mu \mathrm{m}$ ). Patients with bilateral invasive breast cancer and those with tumors of stage cT4, pT4 or $\mathrm{pN} \geq 2$ or known metastatic breast cancer were excluded, as were pregnant women and patients with psychiatric or medical diagnoses potentially interfering with their ability to give informed consent.

\section{Study procedures}

The treating physician then invited the patient to participate in the study, explaining in the discussion the uncertainty surrounding the use of adjuvant chemotherapy in addition to the adjuvant endocrine therapy, and issuing the recommendation of the first tumor board discussion. If the patient agreed to participate in the study, the result of this first discussion was recorded as the "first shared decision". Only after this, breast cancer tissue was sent to Genomic Health Inc. where the ODX RS was determined and returned usually within 7 working days after receipt of the samples. The patient case was then re-presented at the tumor board along with the RS, and a second tumor board recommendation was issued. The RS result and the second tumor board recommendation were then discussed with the patient, and the result of this "second shared decision" was recorded. The "treatment actually given" after the initiation of adjuvant systemic treatment was also recorded. All recommendations (i.e. first tumor board recommendation, first shared decision, second tumor board recommendation, second shared decision) as well as the treatment actually given were classified as either hormonal therapy (HT) or chemotherapy plus endocrine therapy $(\mathrm{CT}+\mathrm{HT})$.

The primary endpoint of the study was the percentage of treatment decisions that changed between the first and second tumor board recommendations (after the inclusion of the RS). Importantly, the investigators contributing patients to the study were blinded to the statistical analysis plan.

The protocol also stratified the patients into two risk groups based on involved nodes (0 versus $1-3)$ and other predefined risk factors taken from the St. Gallen consensus guidelines [5, 29]. These risk factors were: ER-positivity $<50 \%$ and PgR-positivity $<50 \%$, grade 3 , tumor size $>5 \mathrm{~cm}$, extensive lympho-vascular invasion, and Ki67 > 30\%. Patients were deemed to be at low risk of recurrence if they had $\mathrm{pN} 0$ tumor and $\leq 1$ risk factor present or $\mathrm{pN} 1 \mathrm{a}$ with no other risk factor. Patients were non-low risk if they had $\mathrm{pN} 0$ tumor plus $\geq 2$ risk factors, or if pN1a plus $\geq 1$ other risk factor. This risk stratification was held concealed from the participating investigators.

\section{Statistical analyses}

The null hypothesis was that there would be a 5\% change of recommendation in the low-risk group, and a $10 \%$ change of recommendation in the non-low-risk groups, following the second tumor board recommendation. These levels of change were expected to occur independently of the RS. The alternative hypothesis was that a change of recommendation after consideration of the RS would occur in at least $15 \%$ in the low-risk group, and of at least $25 \%$ in the non-low-risk group. These levels of change were set a priori to be considered clinically interesting and relevant. Using these hypotheses and the exact binomial test, assuming a one-sided type I error of 0.025 , a power of $90 \%$, and an expected proportion of non-evaluable patients of $10 \%$, the required sample size was 175 patients in total (93 patients in the low-risk group, 64 patients in the non-low-risk group). When the low-risk group had attained its accrual goal it was decided to continue accrual into both groups in order to keep up the blinding of investigators concerning the concealed statistical analysis plan. The study was closed only when the non-low-risk group was complete.

Point estimates and the corresponding exact 95\% confidence interval were calculated for proportions. Spearman's rank correlation coefficient together with the $95 \%$ confidence interval was calculated for the comparison of scores, while the kappa coefficient with the $95 \%$ confidence interval was calculated to compare categorized scores. SAS 9.2 and R 3.1.0 were used for the statistical analyses.

\section{Results}

Between July 2013 and June 2014 we recruited 229 eligible patients at 18 study sites in Switzerland. Of these, 222 patients were evaluable and 221 patients had a recommendation from both the first and second tumor board and had an ODX RS available (Fig. 1): 154 patients in the low-risk group and 67 patients in the non-low-risk group.

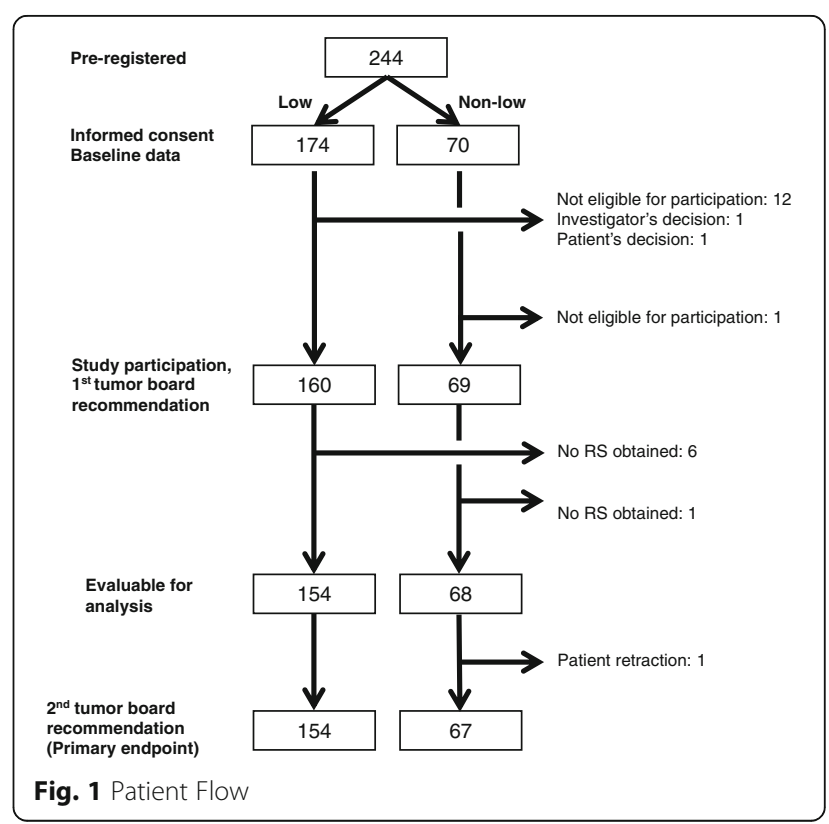


Table 1 Patient characteristics

\begin{tabular}{|c|c|c|c|}
\hline Variable & Low-risk group $(N=160)$ & Non-low-risk group $(N=69)$ & Total $(N=229)$ \\
\hline Age, median (range) & $58(35-82)$ & $58(32-79)$ & $58(32-82)$ \\
\hline \multicolumn{4}{|l|}{ Menopausal status, n (\%) } \\
\hline Premenopausal & $41(26 \%)$ & $23(33 \%)$ & $64(28 \%)$ \\
\hline Peri-menopausal & $5(3 \%)$ & $5(7 \%)$ & $10(4 \%)$ \\
\hline Postmenopausal & $114(71 \%)$ & $41(59 \%)$ & $155(68 \%)$ \\
\hline \multicolumn{4}{|l|}{ pT stage, $n(\%)$} \\
\hline $\mathrm{T} 1$ & $2(1 \%)$ & $2(3 \%)$ & $4(2 \%)$ \\
\hline T1a & $2(1 \%)$ & - & $2(1 \%)$ \\
\hline $\mathrm{T} 1 \mathrm{~b}$ & $19(12 \%)$ & $5(7 \%)$ & $24(10 \%)$ \\
\hline T1c & $75(47 \%)$ & $33(48 \%)$ & $108(47 \%)$ \\
\hline $\mathrm{T} 2$ & $57(36 \%)$ & $23(33 \%)$ & $80(35 \%)$ \\
\hline T3 & $4(3 \%)$ & $6(9 \%)$ & $10(4 \%)$ \\
\hline Tis & $1(1 \%)$ & - & $1(0 \%)$ \\
\hline \multicolumn{4}{|l|}{ pN stage, $n(\%)$} \\
\hline pNO & $122(76 \%)$ & $19(28 \%)$ & $141(62 \%)$ \\
\hline pN1a & $38(24 \%)$ & $50(72 \%)$ & $88(38 \%)$ \\
\hline \multicolumn{4}{|l|}{ Histologic type, n (\%) } \\
\hline Invasive ductal carcinoma & 119 (74\%) & $56(81 \%)$ & $175(76 \%)$ \\
\hline Invasive lobular carcinoma & $31(19 \%)$ & $9(13 \%)$ & $40(17 \%)$ \\
\hline Other & $10(6 \%)$ & $4(6 \%)$ & $14(6 \%)$ \\
\hline \multicolumn{4}{|l|}{ Tumor grade (BRE), $n(\%)$} \\
\hline G 1 & $24(15 \%)$ & $5(7 \%)$ & $29(13 \%)$ \\
\hline G 2 & $124(78 \%)$ & $27(39 \%)$ & $151(66 \%)$ \\
\hline G 3 & $12(8 \%)$ & $37(54 \%)$ & $49(21 \%)$ \\
\hline \multicolumn{4}{|c|}{ Peritumoral lympho-vascular invasion, $n$ (\%) } \\
\hline No & $153(96 \%)$ & $25(36 \%)$ & $178(78 \%)$ \\
\hline Yes & $7(4 \%)$ & $44(64 \%)$ & $51(22 \%)$ \\
\hline
\end{tabular}

Table 2 Distribution of predefined risk factors in the low- and non-low-risk groups (all evaluable patients)

\begin{tabular}{llll}
\hline Variable & Low-risk group $^{\mathrm{a}}(N=154)$ & Non-low-risk group $^{\mathrm{a}}(N=68)^{\mathrm{b}}$ & Total $(N=222)$ \\
\hline N0 & $117(76 \%)$ & $19(28 \%)$ & $136(61 \%)$ \\
N1a & $37(24 \%)$ & $49(72 \%)$ & $96(39 \%)$ \\
PT3 & $3(2 \%)$ & $6(9 \%)$ & $48(22 \%)$ \\
Grade 3 & $12(8 \%)$ & $36(53 \%)$ & $50(23 \%)$ \\
Lympho-vascular invasion & $7(5 \%)$ & $43(63 \%)$ & $1(0 \%)$ \\
ER $<50 \%$ and PgR $<50 \%$ & - & $1(1 \%)$ & $29(13 \%)$ \\
Ki67 $>30 \%$ & $10(6 \%)$ & $19(28 \%)$ & $0.6(0-3)$ \\
Risk factors, mean (range) & $0.2(0-1)$ & $1.6(1-3)$ &
\end{tabular}

Data are $n(\%)$ unless otherwise indicated

${ }^{a}$ Definitions. Low-risk: N0 and $\leq 1$ predefined risk factor, or N1a with no predefined risk factor. Non-low-risk: N0 and $\geq 2$ predefined risk factors, or N1a with $\geq 1$ predefined risk factors (Comment: These classifications were fixed in the protocol but not disclosed to study participants)

${ }^{\mathrm{b}}$ One evaluable patient withdrew from the study before the second tumor board provided a recommendation 
Patient characteristics of all 229 patients entered into the study are shown in Table 1 . Median patient age was 58 years (range 32 to 82). Two thirds of the patients were postmenopausal, pT-stage was mostly T1b, T1c or T2, $21 \%$ of the patients had grade 3 tumors and $22 \%$ had peritumoral lympho-vascular invasion. A total of 88 (38\%) of all patients had 1-3 positive nodes. Histologic type was mostly invasive ductal carcinoma. Risk factors and their distribution among risk groups for the evaluable patients are shown in Table 2. The distribution of ODX low-, intermediate-, and high-risk RS was 65\% (100 of 154), 31\% (48 of 154 ), and $4 \%$ (6 of 154) in the low-risk group and $51 \%$ (34 of 67 ), 28\% (19 of 67), and 21\% (14 of 67) in the nonlow-risk group, respectively.

In the 222 patients evaluable for the primary endpoint, the recommendations of the first and second tumor board differed in $45(20 \%)$ patients: 23 of 154 $(15 \%, 95 \%$ CI $10-22 \%)$ in the low-risk group, and 22 of $68(32 \%, 95 \%$ CI 22-45\%) in the non-low-risk group (Fig. 2). Therefore, in both groups the null hypothesis $(5 \%$ change in the low risk, $10 \%$ change in the non-low risk group) was rejected at the 0.025 level. The $p$-value was $<0.001$ in both groups. Specifically, in the low-risk group, five of 113 (4\%, 95\% CI 1-10\%) patients with an initial HT recommendation were changed to $\mathrm{CT}+\mathrm{HT}$, while 18 of $41(44 \%, 95 \%$ CI $28-60 \%)$ of patients with an initial $\mathrm{CT}+\mathrm{HT}$ recommendation were changed to HT. In the non-low-risk group, three of 19 (16\%, 95\% CI
3-40\%) patients were changed from $\mathrm{HT}$ to $\mathrm{CT}+\mathrm{HT}$, while 19 of $48(40 \%, 95 \%$ CI $26-55 \%)$ were changed from $\mathrm{CH}+\mathrm{HT}$ to $\mathrm{HT}$.

Characteristics of the 8 patients with a change in recommendation from HT to CT + HT can be found in the Appendix (Table 7). Most notably for these 8 patients the median RS (range) was 30 (18-51), showing that RS was a very prominent factor for these 8 decision changes, since half the patients were in the high and the other half in the intermediate risk RS group.

We also investigated how the recommendations of the tumor boards translated into actual patient care. The "evolution" of treatment recommendations from the first tumor board recommendation to the treatment actually given is shown in Table 3 . In addition, we have analyzed the reasons for decision changes in the low-risk/non-low-risk groups (Table 4): Most treatment decision changes were due to the knowledge of RS at the second tumor board (Table 4).

Recommendations of the second tumor board that included knowledge of RS are shown in Table 5. All patients with a high-risk RS (31-100) were recommended to receive CT + HT. Most (124 of 134; 93\%) but not all of the patients with a low RS (0-17) were offered HT only. In the patients with intermediate RS (18-30) tumor board recommendations were variable. Treatment recommendations changed in $22 \%$ of patients with RS $0-17 ; 16 \%$ of patients with RS $18-30$; and $20 \%$ of patients with RS 31-100.

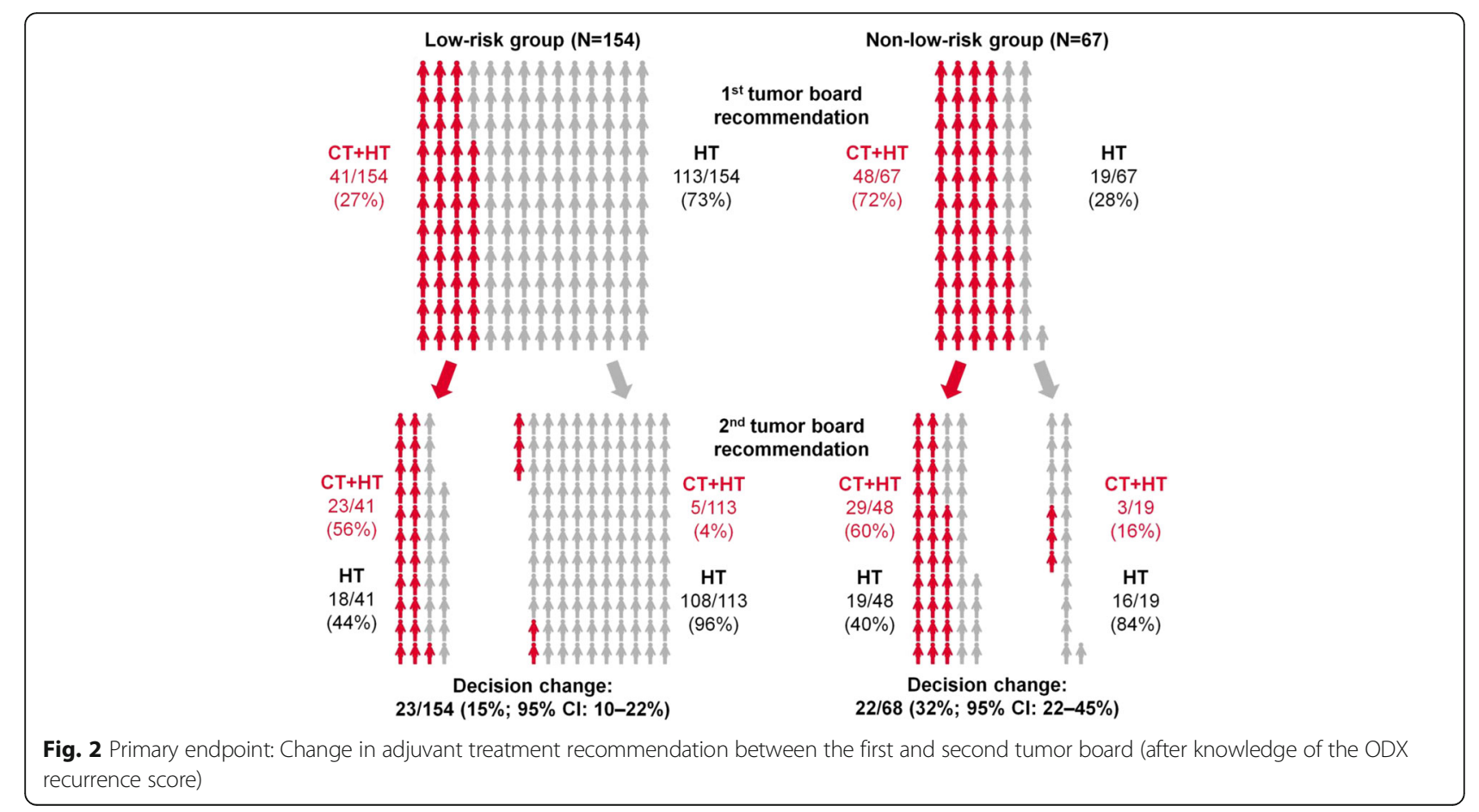


Table 3 Evolution of treatment recommendations

\begin{tabular}{llllll}
\hline Risk category & \multicolumn{2}{l}{$\begin{array}{l}\text { Low-risk group } \\
(N=154)\end{array}$} & & \multicolumn{2}{l}{$\begin{array}{l}\text { Non-low-risk group } \\
(N=67)\end{array}$} \\
\cline { 2 - 3 } Recommendation, $\mathrm{n}$ & $\mathrm{CT}+\mathrm{HT}$ & $\mathrm{HT}$ & & $\mathrm{CT}+\mathrm{HT}$ & $\mathrm{HT}$ \\
\hline 1st tumor board & $41(27 \%)$ & $113(73 \%)$ & & $48(72 \%)$ & $19(28 \%)$ \\
1st shared decision & $40(26 \%)$ & $114(74 \%)$ & & $47(70 \%)$ & $20(30 \%)$ \\
& Add knowledge of recurrence score \\
2nd tumor board & $28(18 \%)$ & $126(82 \%)$ & $32(48 \%)$ & $35(52 \%)$ \\
2nd shared decision & $24(16 \%)$ & $130(84 \%)$ & $32(48 \%)$ & $35(52 \%)$ \\
Treatment actually given & $23(15 \%)$ & $130(84 \%)$ & $28(42 \%)$ & $37(55 \%)$ \\
\hline
\end{tabular}

CT chemotherapy, HT endocrine therapy

The distribution of RS overall as well as for different subgroups can be found in Table 6. A graphic presentation of all the recurrence scores is shown in Fig. 3.

\section{Discussion}

In this multicenter, prospective cohort study of early breast cancer patients we studied how Swiss tumor boards made use of the ODX 21-gene multigene expression assay RS. This assay may be considered for routine use in the USA for all patients with ER-positive/ HER2-negative tumors of at least $5 \mathrm{~mm}$ diameter (T1b and larger) [26]. Our findings suggest that this assay may be used in a more judicious manner, as opposed to testing all patients with early stage ER-positive/HER2negative breast cancer. We found that knowledge of the RS resulted in a very low rate of decision change for patients initially offered HT only, i.e. 5 of $113(4 \%, 95 \%$ CI $1-10 \%)$ in the low-risk group, and 3 of $19(16 \%, 95 \%$ CI $3-40 \%)$ in the non-low-risk group. We therefore think that it is reasonable for these patients to forgo additional testing with the ODX assay, particularly for the patients fulfilling the low-risk criteria (Table 2). Obviously, this statement has to be tempered by the fact that the

Table 4 Reason for change of recommendation

\begin{tabular}{lll}
\hline & $\begin{array}{l}\text { Low-risk group } \\
(N=154)\end{array}$ & $\begin{array}{l}\text { Non-low-risk group } \\
(N=67)\end{array}$ \\
\hline $\begin{array}{l}\text { Number of patients with } \\
\text { decision change, } n\end{array}$ & 23 & 22 \\
$\begin{array}{l}\text { Reasons }{ }^{\text {a }} \text { for decision } \\
\text { change, } n \text { : }\end{array}$ & \\
$\begin{array}{l}\text { Recurrence score } \\
\begin{array}{l}\text { Opinion of tumor } \\
\text { board changed }\end{array}\end{array}$ & $1(4 \%)$ & $21(95 \%)$ \\
Patient preference & $3(13 \%)$ & $1(5 \%)$ \\
Other & $2(9 \%)$ & $1(5 \%)$ \\
\hline
\end{tabular}

${ }^{a}$ More than one reason for changing the treatment decision were possible Further factors analyzed and never found to be a reason for change of recommendation after second tumor board were: Tumor board composition change, new medical information
Table 5 Distribution of second tumor board recommendations according to the recurrence score

\begin{tabular}{|c|c|c|c|c|c|}
\hline \multirow[t]{2}{*}{ Risk category } & \multicolumn{2}{|c|}{$\begin{array}{l}\text { Low-risk } \\
\text { group }(N=154)\end{array}$} & \multicolumn{2}{|c|}{$\begin{array}{l}\text { Non-low-risk } \\
\text { group }(N=67)\end{array}$} & \multirow[t]{2}{*}{ Total } \\
\hline & $\mathrm{CT}+\mathrm{HT}$ & HT & $\mathrm{CT}+\mathrm{HT}$ & $\mathrm{HT}$ & \\
\hline All recommendations & 28 & 126 & 32 & 35 & 221 \\
\hline RS 0-17 (low) & 4 & 96 & 6 & 28 & $134(61 \%)$ \\
\hline RS 18-30 (intermediate) & 18 & 30 & 12 & 7 & $67(30 \%)$ \\
\hline RS 31-100 (high) & 6 & 0 & 14 & 0 & $20(9 \%)$ \\
\hline
\end{tabular}

confidence intervals are large, and that the primary decision to recommend HT only is subjective and may not be applicable to other centers. On the other hand, patients initially considered for CT + HT have a high likelihood of decision change based on the knowledge of the RS, with 18 of 41 (44\%) in the low-risk and 19 of 48 $(40 \%)$ in the non-low-risk group. These patients at non low-risk as defined by our criteria may be considered good candidates to have ODX testing.

Overall, our data show that the ODX assay, when readily available, significantly impacts adjuvant treatment decisions in patients with ER-positive/HER2-negative early breast cancer. Changes in treatment recommendations at the second tumor board were predominantly driven by the availability of the RS. When considering the entire study population treatment decisions changed in approximately $20 \%$ of patients, which is somewhat lower than the level of change seen in other studies [9, 11-18]. A recent meta-analysis of 15

Table 6 Distribution of RS overall and for different subgroups

\begin{tabular}{ll}
\hline Variable & RS median (range) \\
\hline All patients, $N=222$ & $16(0-68)$ \\
Tumor grade (BRE) & $14(6-28)$ \\
G1, $N=28$ & $15(0-51)$ \\
G2, $N=146$ & $24(5-68)$ \\
G3, $N=48$ & \\
pN stage & $17(0-68)$ \\
pNo, $N=136$ & $14(0-51)$ \\
pN1a, $N=86$ & \\
Peritumoral lympho-vascular invasion & $16(0-68)$ \\
No, $N=172$ & $15(2-44)$ \\
Yes, $N=50$ & \\
Invasive tumor size & $15(0-43)$ \\
$\leq 2 \mathrm{~cm}, N=133$ & $16(0-68)$ \\
$>2 \mathrm{~cm}, N=89$ & \\
Ki67 & \\
$\leq 30, N=193$ & $15(0-51)$ \\
$>30, N=29$ & $24(1-68)$ \\
\hline
\end{tabular}




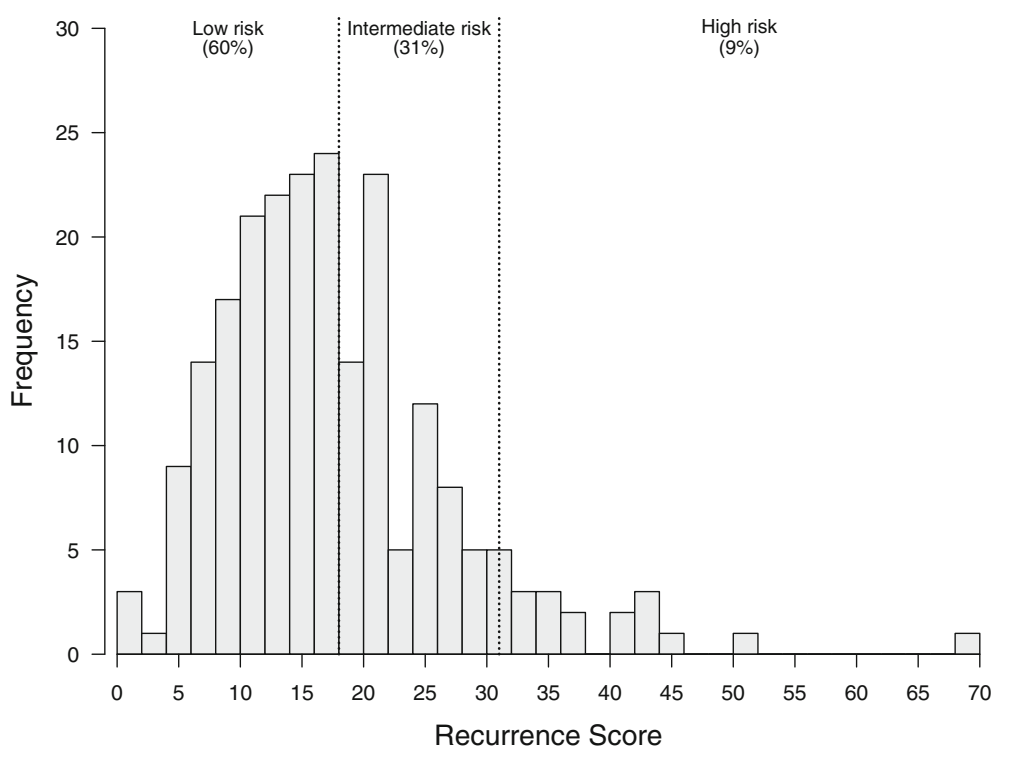

Fig. 3 Distribution of Recurrence Score

studies that investigated the impact of the ODX assay on adjuvant treatment decisions reported that the additional information provided by the RS changed the recommendation for adjuvant treatment in $30 \%$ of cases [30]. The lower rate of decision changes in our study may reflect the fact that the assay was not applied to all patients who satisfied the inclusion criteria. Investigators were free not to offer study participation to patients. Investigators were also free in their interpretation of the RS which leaves ambiguity particularly in the intermediate-risk group (RS 18-30).The observation that the majority of treatment decision changes resulted in a de-escalation of chemoendocrine therapy to adjuvant endocrine therapy alone is consistent with other studies. Overall, the proportion of patients for whom chemotherapy was recommended was reduced from $40.3 \%(89 / 221)$ at the first tumor board to $27.1 \%(60 / 221)$ at the second tumor board (a 13.2\% net reduction). These data are similar to the findings of the meta analysis from Augustovski et al. [30] and a pooled analysis of four studies by Albanell et al. [31] which reported net reductions in recommendations for chemotherapy of $12 \%$ and $13.5 \%$, respectively. In a recent large population-based cohort study of almost 1000 patients from Ontario (Canada) ODX-testing changed the oncologists' recommendations in half the patients. However this study included a pretest category of "unsure" (whether chemotherapy should be given) which accounted for 328 of 508 patients $(65 \%)$ who had a change in recommendation. This large study confirms that ODX is far more likely to change the recommendation to omitting chemotherapy (38\%) than to recommending it (15\%) [32].

Our data are also in agreement with recent recommendations from the 14th St Gallen International Breast
Cancer Conference [33]. These guidelines support omitting adjuvant chemotherapy in patients with a low probability of recurrence as determined by multigene expression profiling techniques. At the same time these guidelines caution that adjuvant chemotherapy may be justified in patients with poor pathologic features even if they have a favorable multigene assay result.

Other multi-gene tests and the standardized immunohistochemistry-based scoring system IHC 4 have also been useful in particular to divide patients at intermediate risk for relapse into groups at higher risk and at lower risk [34]. One study suggests that the amount of prognostic information contained in four widely performed immunohistochemical (IHC) assays is similar to that in a multi-gene test [35]. Moreover a study comparing several multi-gene tests to IHC4 (using semiquantitative assessment) showed that the IHC4 score provides better prognostic information than the corresponding quantitative RNA measurements [36]. Thus the combination of quality controlled conventional IHC tests and multigene signatures may provide more information for some patients at intermediate risk of relapse.

Our study has strengths and limitations. Strengths include the prospective nature of the study, prospectively defined endpoints, hypotheses and sample size planning, the formal requirement of the presence of the pathologist at the multidisciplinary tumor-board, the documentation of the multi-step decision-making and implementation process and the trial sponsoring by an academic group (SAKK). On the other hand, observational studies have well-known limitations. When planned prospectively, studies are subject to selection bias. In observational studies investigators will influence study results when they are 
subject of the investigation and if they are not blinded for the study endpoints and study goals. Furthermore, unobservable and unobserved factors not included in the analyses, are likely to play a role in the patterns and results observed.

\section{Conclusion}

In conclusion, we suggest that patients given a recommendation of HT by a Swiss tumor board may forgo ODX testing, especially if categorized as low risk by the criteria listed in the legend of Table 2. By contrast, in patients recommended $\mathrm{CT}+\mathrm{HT}$, knowledge of RS had considerable potential to change treatment recommendations in both risk groups of our patients.

\section{Appendix}

Table 7 Characteristics of patients with recommendation change from HT to $\mathrm{CT}+\mathrm{HT}$

\begin{tabular}{ll}
\hline Variable & Value $(N=8)$ \\
\hline Recurrence score, median (range) & $30(18-51)$ \\
Risk group, $n(\%)$ & \\
Low risk & $5(63 \%)$ \\
Non-low risk & $3(38 \%)$ \\
Age, median (range) & $61(44-73)$
\end{tabular}

\section{Menopausal status, n (\%)}

Premenopausal

Postmenopausal

pT stage, $n(\%)$

$\mathrm{T} 1 \mathrm{~b}$

T1C

T2

pN stage, $n(\%)$

\section{pNO}

pN1a

\section{Histologic type, $n$ (\%)}

Invasive ductal carcinoma

Tumor grade (BRE), $n$ (\%)

Peritumoral lympho-vascular invasion, $n(\%)$

No

Yes

\section{Abbreviations}

$\mathrm{CT}+\mathrm{HT}$ : Chemotherapy plus hormonal therapy; HT: Hormonal therapy; LR: Low-risk; NLR: Non-low-risk; ODX: Oncotype DX ; RC: Recommendation change; RS: Recurrence Score ${ }^{\oplus}$; SAKK: Swiss Group for Clinical Cancer Research; SERI: Swiss State Secretariat for Education, Research and Innovation; TB: Tumor board

\section{Acknowledgements}

We are grateful to Genomic Health Inc. which provided the ODX tests free of charge for all patients. Genomic Health Inc. did not contribute to the study design, the study conduct, the study analysis, nor the preparation of the manuscript. However, Genomic Health Inc. was offered to comment on the manuscript. In addition, we should like to acknowledge the help of the medical writer Jamie Ashman from Prism Ideas in the preparation of the manuscript. This work was supported in part by the Swiss State Secretariat for Education, Research and Innovation (SERI).

Availability of data and materials

The data will not be shared because of privacy concerns of patients and independence of treating physicians.

\section{Authors' contributions}

$\mathrm{BCP}$ and SA conceived the study, participated in the design of the study, and drafted the manuscript. CT, KJD, CRo, SZ, RvM, RW, TR, AM, KB, MBo, UN, $\mathrm{CU}, \mathrm{BS}$, and CRa have made substantial contribution to acquisition of data and interpretation of the data. MBi has made substantial contribution to interpretation of the data, performed the statistical analysis, and helped to draft the manuscript. VB and SBV participated in the design and coordination of the study and have made substantial contribution to interpretation of the data. All authors read and approved the final manuscript.

\section{Competing interests}

BCP has received lecture fees from Genomic Health Inc. TR is associate editor for BMC cancer. The other authors declare no conflicts of interest.

\section{Consent for publication}

The study was approved by the cantonal ethics committee of Zurich (2013-0228) and the Institutional Review Boards at all participating centers.

\section{Ethics approval and consent to participate}

The study was conducted in accordance with the principals of the Declaration of Helsinki [28]. All patients provided written informed consent. The Swiss cantonal ethics committees of Bern, Aargau, Basel, Lucerne, St. Gallen, Thurgau, Ticino, Vaud and Zurich approved the study.

\section{Publisher's Note}

Springer Nature remains neutral with regard to jurisdictional claims in published maps and institutional affiliations.

\section{Author details}

${ }^{1}$ Universitaetsspital Zuerich, Raemistrasse 100, 8091 Zurich, Switzerland. ${ }^{2}$ Brustzentrum Zuerich, Zurich, Switzerland. ${ }^{3}$ Universitaetsspital Basel, Basel, Switzerland. ${ }^{4}$ Hôpital Cantonal Fribourg, Fribourg, Switzerland. ${ }^{5}$ Kantonsspital Graubuenden Chur, Chur, Switzerland. 'Euzerner Kantonsspital, Lucerne, Switzerland. ${ }^{7}$ Breast Center St. Gallen, St. Gallen, Switzerland. ${ }^{8}$ Kantonsspital Winterthur, Winterthur, Switzerland. ${ }^{9}$ Engeriedspital Bern, Bern, Switzerland. ${ }^{10}$ Spitalzentrum Biel, Biel, Switzerland. ${ }^{11}$ Inselspital Bern, Bern, Switzerland. ${ }^{12}$ Kantonsspital Olten, Olten, Switzerland. ${ }^{13}$ Kantonsspital Baselland, Liestal, Switzerland. ${ }^{14}$ SAKK Coordinating Center, Bern, Switzerland.

Received: 18 March 2016 Accepted: 4 April 2017

Published online: 13 April 2017

\section{References}

1. Thurlimann B, Price KN, Gelber RD, Holmberg SB, Crivellari D, Colleoni M, Collins J, Forbes JF, Castiglione-Gertsch M, Coates AS, Goldhirsch A. Is chemotherapy necessary for premenopausal women with lower-risk nodepositive, endocrine responsive breast cancer? 10-year update of international breast cancer study group trial 11-93. Breast Cancer Res Treat. 2009;113:137-44. doi:10.1007/s10549-008-9912-9. 
2. Berry DA, Cirrincione C, Henderson IC, Citron ML, Budman DR, Goldstein L, Martino S, Perez EA, Muss HB, Norton L, Hudis C, Winer EP. Estrogen-receptor status and outcomes of modern chemotherapy for patients with node-positive breast cancer. JAMA. 2006;295:1658-67. do:10.1001/jama.295.14.1658.

3. Hayes DF, Thor AD, Dressler LG, Weaver D, Edgerton S, Cowan D, Broadwater G, Goldstein $\sqcup$, Martino S, Ingle JN, Henderson IC, Norton L, Winer EP, Hudis CA, Ellis MJ, Berry DA. HER2 and response to paclitaxel in node-positive breast cancer. N Engl J Med. 2007;357:1496-506. doi:10.1056/NEJMoa071167.

4. Gnant M, Mlineritsch B, Stoeger H, Luschin-Ebengreuth G, Heck D, Menzel C, Jakesz R, Seifert M, Hubalek M, Pristauz G, Bauernhofer T, Eidtmann H, Eiermann W, Steger G, Kwasny W, Dubsky P, Hochreiner G, Forsthuber EP, Fesl C, Greil R. Adjuvant endocrine therapy plus zoledronic acid in premenopausal women with early-stage breast cancer: 62-month follow-up from the ABCSG-12 randomised trial. Lancet Oncol. 2011;12:631-41. doi:10. 1016/S1470-2045(11)70122-X.

5. Goldhirsch A, Ingle JN, Gelber RD, Coates AS, Thurlimann B, Senn HJ. Thresholds for therapies: highlights of the St Gallen international expert consensus on the primary therapy of early breast cancer 2009. Ann Oncol. 2009:20:1319-29. doi:10.1093/annonc/mdp322.

6. Paik S, Tang G, Shak S, Kim C, Baker J, Kim W, Cronin M, Baehner FL, Watson D, Bryant J, Costantino JP, Geyer Jr CE, Wickerham DL, Wolmark N. Gene expression and benefit of chemotherapy in women with node-negative, estrogen receptor-positive breast cancer. J Clin Oncol. 2006;24:3726-34. doi:10.1200/JCO.2005.04.7985.

7. Albain KS, Barlow WE, Shak S, Hortobagyi GN, Livingston RB, Yeh IT, Ravdin P, Bugarini R, Baehner FL, Davidson NE, Sledge GW, Winer EP, Hudis C, Ingle JN, Perez EA, Pritchard KI, Shepherd L, Gralow JR, Yoshizawa C, Allred DC, Osborne CK, Hayes DF. Prognostic and predictive value of the 21-gene recurrence score assay in postmenopausal women with node-positive, oestrogen-receptor-positive breast cancer on chemotherapy: a retrospective analysis of a randomised trial. Lancet Oncol. 2010;11:55-65. doi:10.1016/ S1470-2045(09)70314-6.

8. Paik S, Shak S, Tang G, Kim C, Baker J, Cronin M, Baehner FL, Walker MG, Watson D, Park T, Hiller W, Fisher ER, Wickerham DL, Bryant J, Wolmark N. A multigene assay to predict recurrence of tamoxifen-treated, node-negative breast cancer. N Engl J Med. 2004;351:2817-26. doi:10.1056/NEJMoa041588.

9. Habel LA, Shak S, Jacobs MK, Capra A, Alexander C, Pho M, Baker J, Walker M, Watson D, Hackett J, Blick NT, Greenberg D, Fehrenbacher L, Langholz B, Quesenberry CP. A population-based study of tumor gene expression and risk of breast cancer death among lymph node-negative patients. Breast Cancer Res. 2006;8:R25. doi:10.1186/bcr1412.

10. Toi M, Iwata H, Yamanaka T, Masuda N, Ohno S, Nakamura S, Nakayama T, Kashiwaba M, Kamigaki S, Kuroi K. Clinical significance of the 21-gene signature (Oncotype DX) in hormone receptor-positive early stage primary breast cancer in the Japanese population. Cancer. 2010:116:3112-8. doi:10.1002/cncr.25206

11. Sparano JA, Gray RJ, Makower DF, Pritchard KI, Albain KS, Hayes DF, Geyer Jr CE, Dees EC, Perez EA, Olson Jr JA, Zujewski J, Lively T, Badve SS, Saphner TJ, Wagner LI, Whelan TJ, Ellis MJ, Paik S, Wood WC, Ravdin P, Keane MM, Gomez Moreno HL, Reddy PS, Goggins TF, Mayer IA, Brufsky AM, Toppmeyer DL, Kaklamani VG, Atkins JN, Berenberg JL, Sledge GW. Prospective validation of a 21-Gene expression assay in breast cancer. N Engl J Med. 2015:373:2005-14. doi:10.1056/NEJMoa1510764.

12. Dowsett M, Cuzick J, Wale C, Forbes J, Mallon EA, Salter J, Quinn E, Dunbier A, Baum M, Buzdar A, Howell A, Bugarini R, Baehner FL, Shak S. Prediction of risk of distant recurrence using the 21-gene recurrence score in nodenegative and node-positive postmenopausal patients with breast cancer treated with anastrozole or tamoxifen: a TransATAC study. J Clin Oncol. 2010:28:1829-34. doi:10.1200/JCO.2009.24.4798.

13. Harris L, Fritsche H, Mennel R, Norton L, Ravdin P, Taube S, Somerfield MR, Hayes DF, Bast Jr RC. American Society of Clinical Oncology 2007 update of recommendations for the use of tumor markers in breast cancer. J Clin Oncol. 2007;25:5287-312. doi:10.1200/JCO.2007.14.2364.

14. Lo SS, Mumby PB, Norton J, Rychlik K, Smerage J, Kash J, Chew HK, Gaynor ER, Hayes DF, Epstein A, Albain KS. Prospective multicenter study of the impact of the 21-gene recurrence score assay on medical oncologist and patient adjuvant breast cancer treatment selection. J Clin Oncol. 2010;28:1671-6. doi:10.1200/JCO.2008.20.2119.

15. Brauchli P, Thurlimann B, Crowe SN, Herrmann R. What is the value of the 21-gene recurrence score? J Clin Oncol. 2010;28:e671-2. doi:10.1200/JCO. 2010.30.3313.
16. de Boer RH, Baker C, Speakman D, Chao CY, Yoshizawa C, Mann GB. The impact of a genomic assay (Oncotype DX) on adjuvant treatment recommendations in early breast cancer. Med J Aust. 2013;199:205-8. doi:10.5694/mja12.11334.

17. Davidson JA, Cromwell I, Ellard SL, Lohrisch C, Gelmon KA, Shenkier T, Villa D, Lim H, Sun S, Taylor S, Taylor M, Czerkawski B, Hayes M, lonescu DN, Yoshizawa C, Chao C, Peacock S, Chia SK. A prospective clinical utility and pharmacoeconomic study of the impact of the 21-gene recurrence score(R) assay in oestrogen receptor positive node negative breast cancer. Eur J Cancer. 2013:49:2469-75. doi:10.1016/j.ejca.2013.03.009.

18. Eiermann W, Rezai M, Kummel S, Kuhn T, Warm M, Friedrichs K, Schneeweiss A, Markmann S, Eggemann H, Hilfrich J, Jackisch C, Witzel I, Eidtmann H, Bachinger A, Hell S, Blohmer J. The 21-gene recurrence score assay impacts adjuvant therapy recommendations for ER-positive, node-negative and nodepositive early breast cancer resulting in a risk-adapted change in chemotherapy use. Ann Oncol. 2013;24:618-24. doi:10.1093/annonc/mds512.

19. Gligorov J, Pivot XB, Jacot W, Naman HL, Spaeth D, Misset JL, Largillier R, Sautiere $J$, de Roquancourt A, Pomel C, Rouanet P, Rouzier R, PenaultLlorca FM. Prospective clinical utility study of the use of the 21-Gene assay in adjuvant clinical decision making in women with estrogen receptorpositive early invasive breast cancer: results from the SWITCH study. Oncologist. 2015;20:873-9. doi:10.1634/theoncologist.2014-0467.

20. Stemmer SM, Klang SH, Ben-Baruch N, Geffen DB, Steiner M, SoussanGutman L, Merling S, Svedman C, Rizel S, Lieberman N. The impact of the 21-gene recurrence score assay on clinical decision-making in node-positive (up to 3 positive nodes) estrogen receptor-positive breast cancer patients. Breast Cancer Res Treat. 2013;140:83-92. doi:10.1007/s10549-013-2603-1.

21. Yamauchi H, Nakagawa C, Takei H, Chao C, Yoshizawa C, Yagata H, Yoshida A, Hayashi N, Hell S, Nakamura S. Prospective study of the effect of the 21gene assay on adjuvant clinical decision-making in Japanese women with estrogen receptor-positive, node-negative, and node-positive breast cancer. Clin Breast Cancer. 2014;14:191-7. doi:10.1016/j.clbc.2013.10.017.

22. Albanell J, Gonzalez A, Ruiz-Borrego M, Alba E, Garcia-Saenz JA, Corominas JM, Burgues O, Furio V, Rojo A, Palacios J, Bermejo B, Martinez-Garcia M, Limon ML, Munoz AS, Martin M, Tusquets I, Rojo F, Colomer R, Faull I, Lluch A. Prospective transGEICAM study of the impact of the 21-gene recurrence score assay and traditional clinicopathological factors on adjuvant clinical decision making in women with estrogen receptor-positive (ER+) node-negative breast cancer. Ann Oncol. 2012;23:625-31. doi:10.1093/annonc/mdr278.

23. Holt S, Bertelli G, Humphreys I, Valentine W, Durrani S, Pudney D, Rolles M, Moe M, Khawaja S, Sharaiha Y, Brinkworth E, Whelan S, Jones S, Bennett H, Phillips CJ. A decision impact, decision conflict and economic assessment of routine Oncotype DX testing of 146 women with node-negative or pNImi, ER-positive breast cancer in the U.K. Br J Cancer. 2013;108:2250-8. doi:10.1038/bjc.2013.207.

24. Penault-Llorca F, Andre F, Sagan C, Lacroix-Triki M, Denoux Y, Verriele V, Jacquemier J, Baranzelli MC, Bibeau F, Antoine M, Lagarde N, Martin AL, Asselain B, Roche H. Ki67 expression and docetaxel efficacy in patients with estrogen receptor-positive breast cancer. J Clin Oncol. 2009;27:2809-15. doi:10.1200/JCO.2008.18.2808.

25. Joerger M, Thurlimann B, Savidan A, Frick H, Bouchardy C, Konzelmann I, Probst-Hensch N, Ess S. A population-based study on the implementation of treatment recommendations for chemotherapy in early breast cancer. Clin Breast Cancer. 2012;12:102-9. doi:10.1016/j.clbc.2011.10.005.

26. National Comprehensive Cancer Network. Guidelines on Invasive Breast Cancer. 2013. Version 2 http://www.nccn.org/professionals/physician_gls/ pdf/breast.pdf. Accessed 17 Aug 2015.

27. Edge SB, Compton CC. The American joint committee on cancer: the 7th edition of the AJCC cancer staging manual and the future of TNM. Ann Surg Oncol. 2010;17:1471-4. doi:10.1245/s10434-010-0985-4.

28. Williams JR. The declaration of Helsinki and public health. Bull World Health Organ. 2008;86:650-2. doi:10.1590/50042-96862008000800022.

29. Goldhirsch A, Wood WC, Coates AS, Gelber RD, Thurlimann B, Senn HJ. Strategies for subtypes-dealing with the diversity of breast cancer: highlights of the St. Gallen international expert consensus on the primary therapy of early breast cancer 2011. Ann Oncol. 2011;22:1736-47. doi:10.1093/annonc/mdr304.

30. Augustovski F, Soto N, Caporale J, Gonzalez L, Gibbons L, Ciapponi A. Decisionmaking impact on adjuvant chemotherapy allocation in early node-negative breast cancer with a 21-gene assay: systematic review and meta-analysis. Breast Cancer Res Treat. 2015;152:611-25. doi:10.1007/s10549-015-3483-3.

31. Albanell J, Gligorov J, Holt S, Blohmer J, Eiermann W, Svedman C. Pooled analysis of 4 European studies assessing the impact of Oncotype DX on treatment decisions. Breast. 2013;22:562. 
32. Levine MN, Julian JA, Bedard PL, Eisen A, Trudeau ME, Higgins B, Bordeleau L, Pritchard Kl. Prospective evaluation of the 21-Gene recurrence score assay for breast cancer decision-making in Ontario. J Clin Oncol. 2015;34:1065-72.

33. Coates AS, Winer EP, Goldhirsch A, Gelber RD, Gnant M, Piccart-Gebhart M, Thurlimann B, Senn HJ. Tailoring therapies-improving the management of early breast cancer: St Gallen international expert consensus on the primary therapy of early breast cancer 2015. Ann Oncol. 2015;26:1533-46. doi:10.1093/annonc/mdv221.

34. Barton S, Zabaglo L, A'Hern R, Turner N, Ferguson T, O'Neill S, Hills M, Smith I, Dowsett M. Assessment of the contribution of the $\mathrm{IHC}+\mathrm{C}$ score to decision making in clinical practice in early breast cancer. $\mathrm{Br} J$ Cancer. 2012;106:1760-5. doi:10.1038/bjc.2012.166.

35. Cuzick J, Dowsett M, Pineda S, Wale C, Salter J, Quinn E, Zabaglo L, Mallon E, Green AR, Ellis IO, Howell A, Buzdar AU, Forbes JF. Prognostic value of a combined estrogen receptor, progesterone receptor, Ki-67, and human epidermal growth factor receptor 2 immunohistochemical score and comparison with the Genomic Health recurrence score in early breast cancer. J Clin Oncol. 2011;29:4273-8. doi:10.1200/JCO.2010.31.2835.

36. Yamamoto-lbusuki M, Yamamoto $Y$, Yamamoto S, Fujiwara S, Fu P, Honda $Y$, lyama K, Iwase H. Comparison of prognostic values between combined immunohistochemical score of estrogen receptor, progesterone receptor, human epidermal growth factor receptor 2, $\mathrm{Ki}-67$ and the corresponding gene expression score in breast cancer. Mod Pathol. 2013;26:79-86. doi:10.1038/modpathol.2012.151.

\section{Submit your next manuscript to BioMed Central and we will help you at every step:}

- We accept pre-submission inquiries

- Our selector tool helps you to find the most relevant journal

- We provide round the clock customer support

- Convenient online submission

- Thorough peer review

- Inclusion in PubMed and all major indexing services

- Maximum visibility for your research

Submit your manuscript at www.biomedcentral.com/submit 